\title{
MORPHOMETRICS, OVARY STRUCTURE, AND PARASITES OF CHIASMODON HARTELI (ACTINOPTERYGII: TRACHINIFORMES: CHIASMODONTIDAE) FROM OFF SOUTH-EASTERN GREENLAND
}

\author{
Beata WIĘCASZEK ${ }^{1 *}$, Marcelo R.S. MELO ${ }^{2}$, Joanna SZULC ${ }^{1}$, and Ewa SOBECKA ${ }^{1}$ \\ ${ }^{1}$ Division of Hydrobiology, Ichthyology and Biotechnology of Breeding, Faculty of Food Sciences and Fisheries, \\ West Pomeranian University of Technology, Szczecin, Poland \\ ${ }^{2}$ Universidade Federal de São Paulo, Campus Diadema, Departamento de Ciências Exatas e da Terra, \\ Rua Prof. Arthur Riedel, 275 Eldorado, 09972-270, Diadema, SP, Brazil
}

Więcaszek B., Melo M.R.S., Szulc J., Sobecka E. 2011. Morphometrics, ovary structure, and parasites of Chiasmodon harteli (Actinopterygii: Trachiniformes: Chiasmodontidae) from off south-eastern Greenland. Acta Ichthyol. Piscat. 41 (4): 301-306.

\begin{abstract}
Background. Chiasmodon harteli Melo, 2009 is a rarely captured deepwater fish. Even though the taxonomy of this genus is fairly well resolved, very little is known about the biology of individual Chiasmodon species. The objective of the presently reported study was to supplement new knowledge on C. harteli.

Materials and methods. A single female specimen of C. harteli was captured on 1 July 2008 off the south-eastern coast of Greenland during bottom trawling at the depth of $1000 \mathrm{~m}$. Morphometric and meristic data were collected and absolute values of the measurements [to the nearest $0.1 \mathrm{~mm}$ ] were also related to the fish standard length and head length. To determine the gonad maturity stage, ovaries were fixed in Bouin's solution and buffered formalin (4\%), dehydrated, embedded in paraffin wax, cut into 5- $\mu \mathrm{m}$ histological sections and finally stained with haematoxylin and eosin. Parasitological examinations covered the skin, eyes, mouth, nasal cavities, gills, gonads, spleen, gastrointestinal tract, liver, kidneys, peritoneum, and muscles. Parasites recovered were preserved in $70 \%$ ethanol.

Results. Detailed morphometrics, including metric and meristic data, as well as dentition formula, are provided. The individual studied was a mature female. The ovaries were in stage I (Merson scale) (mature, featuring oocytes in early vitellogenesis and oogonies). The mean oocyte cell diameter was $84.62 \pm 4.67 \mu \mathrm{m}$, while the range: $45.05-114.08 \mu \mathrm{m}$. The fish hosted only one parasite species-Anisakis simplex (Nematoda; encysted L3 larvae). The stomach of the specimen studied was enlarged, although completely empty.

Conclusion. This is the first substantiated record of this species since its original description in 2009. The structure of female gonads of $C$. harteli was described here for the first time. The acquired data on the gonadal development may shed new light on the species' reproduction and may help to approximate the spawning time. The nematode A. simplex were reported herein for the first time in a Chiasmodon.
\end{abstract}

Keywords: swallower, morphometrics, gonads, Anisakis simplex, deep-sea, North Atlantic

\section{INTRODUCTION}

Chiasmodon Johnson, 1864 is a genus of meso- and bathypelagic fishes commonly known as swallowers, due to their ability to swallow prey larger than their own body (Johnson and Keene 1986). The genus was recently revised by Melo (2009), who recognized seven valid species. Wiley and Johnson (2010) placed Chiasmodontidae in the order Trachiniformes. The fishes of this genus have a wide distribution in the Atlantic, Pacific, Indian-, and Southern Oceans, with some species having endemic areas of distribution. For instance, Chiasmodon harteli Melo, 2009-a rarely captured deepwater fish species - is restricted to the cold waters of the North Atlantic and is the only species occurring off Greenland (Melo 2009, Møller et al. 2010). Even though the taxonomy of this genus is fairly well resolved, very little is known about the biology of individual Chiasmodon species. No information was published on reproductive biology of $C$. harteli and no parasites, identified to the species level, have been reported from swallowers. The objective of presently reported study was to provide new information on biology of $C$. harteli.

\section{MATERIAL AND METHODS}

A single female specimen of Chiasmodon harteli, was

\footnotetext{
${ }^{*}$ Correspondence: Dr Beata Więcaszek, Katedra Hydrobiologii, Ichtiologii i Biotechnologii Rozrodu, Wydział Nauk o Żywności i Rybactwa, Zachodniopomorski Uniwersytet Technologiczny, ul. Kazimierza Królewicza 4, 71-550 Szczecin, Poland, phone: +4891 449 6637, fax: +4891 449 6657, e-mail: beata.wiecaszek@zut.edu.pl.
} 
collected on 1 July 2008 off the south-eastern coast of Greenland (lat $63^{\circ} 10^{\prime} \mathrm{N}$, long $40^{\circ} 01^{\prime} \mathrm{W}$ ), as a by-catch during a commercial fisheries cruise targeting Greenland halibut, Reinhardtius hippoglossoides (Walbaum, 1792), during bottom trawling, at the depth of $1000 \mathrm{~m}$. Morphometric and meristic data were obtained following the protocol described by Melo et al. (2007). Measurements were recorded to the nearest $0.1 \mathrm{~mm}$ using digital callipers. The absolute values were also supplemented by the values related to standard length (SL) of the fish and the head length (HL). To determine the gonad maturity stage, histological methods, following Zha et al. (2007), were implemented. Ovaries were fixed in Bouin's solution and buffered formalin (4\%), dehydrated, embedded in paraffin wax, cut into $5-\mu \mathrm{m}$ histological sections and finally stained with haematoxylin and eosin. The sections of paraffin blocks were examined microscopically. Fifty-five oocytes were measured. Stages of gonad maturation were determined following Merson et al. (2000). Photographs of the ovary structure were taken using Nikon Eclipse TE 2000-S and NIS Elements Br Software.

Parasitological examinations were focused on the skin, eye (lens and vitreous humour), mouth, nasal cavities, gills, gonads, spleen, gastrointestinal tract, liver, kidneys, peritoneum, and muscles. The parasites recovered were preserved in $70 \%$ ethanol. Identification was made by viewing the specimens in transient light.

The specimen was deposited in the collection of the Division of Hydrobiology, Ichthyology and Biotechnology of Breeding, Faculty of Food Sciences and Fisheries, West Pomeranian University of Technology, Szczecin, Poland (DFS/4-3-38-6-1).

\section{RESULTS}

The studied specimen of Chiasmodon harteli (Fig. 1) was 161.0-mm long (standard length) and weighed $27.6 \mathrm{~g}$. Morphometric data are summarized in Table 1, while meristic data in Table 2. General body shape and dentition were as described by Melo (2009). Teeth were present on premaxilla, dentary, palatine, second basibranchial, upper pharyngobranchial and fifth ceratobranchial. Premaxillary head is with one accessory tooth, one canine at anterior tip and one fang at ventral part; premaxillary body is with 21 teeth in lateral series and four teeth in mesial series, the first tooth being the largest; dentary teeth are with one canine, sixteen teeth in lateral series, and eight teeth in mesial series (Fig. 2). Six palatine teeth and four basibranchial teeth were recorded.

The individual was a mature female, with ovaries in the stage I of development (Figs. 3-4). Both oocytes and oogonies were present in the ovaries, the oocytes being predominant. The oocytes were in early vitellogenesis. The nucleus was situated in the centre of oocyte, with drops of fat and cortex seeds. Yolk was recently formed in the vitellogenic follicles, which was indicated by the oocytes being stained in eosin (Fig. 3). The mean cell diameter was $84.62 \mu \mathrm{m}( \pm 4.67)$, with the smallest oocyte $45.05 \mu \mathrm{m}$ and the largest $114.08 \mu \mathrm{m}$. A small amount

Table 1

Morphometric data of Chiasmodon harteli

\begin{tabular}{|c|c|c|c|c|}
\hline & Character & This study & $\begin{array}{l}\text { Species range } \\
\text { (Melo 2009) }\end{array}$ & $\begin{array}{c}\text { Mean } \\
\text { (Melo 2009) } \\
\end{array}$ \\
\hline \multirow{2}{*}{$\gtrless$} & Standard length [mm] & 161.0 & $46.4-198.3$ & 137.4 \\
\hline & Head length [mm] & 42.5 & $12.3-50.7$ & 36.6 \\
\hline \multirow{8}{*}{ 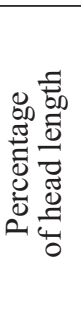 } & Snout & 30.8 & $23.0-26.6$ & 24.9 \\
\hline & Upper jaw & 72.9 & $74.3-84.2$ & 77.9 \\
\hline & Lower jaw & 77.7 & $80.8-89.9$ & 84.5 \\
\hline & Orbit width & 19.9 & $13.7-24.7$ & 16.3 \\
\hline & Orbit height & 18.8 & $12.7-19.3$ & 14.2 \\
\hline & Distance between nostrils & 10.1 & $6.7-9.6$ & 7.8 \\
\hline & Interorbital distance & 22.4 & $17.0-20.0$ & 18.5 \\
\hline & Head width & 29.2 & $26.8-34.8$ & 29.2 \\
\hline \multirow{15}{*}{ 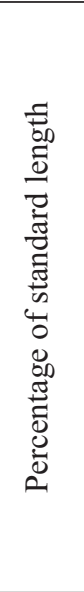 } & Head length & 26.4 & $25.0-28.8$ & 26.7 \\
\hline & Body width & 8.3 & $4.5-8.9$ & 6.6 \\
\hline & Insertion of pectoral fin & 27.5 & $26.0-30.7$ & 28.7 \\
\hline & Insertion of ventral fin & 30.2 & $25.9-33.7$ & 30.5 \\
\hline & Pectoral fin length & 17.9 & $14.1-20.8$ & 16.8 \\
\hline & Pelvic fin length & 10.9 & $7.8-11.8$ & 10.0 \\
\hline & Origin of first dorsal fin & 33.8 & $31.0-35.5$ & 32.8 \\
\hline & Base of first dorsal fin & 16.3 & $11.7-20.9$ & 16.1 \\
\hline & First dorsal fin depth & 7.4 & $6.9-11.4$ & 8.7 \\
\hline & Origin of second dorsal & 51.4 & $49.0-56.3$ & 51.2 \\
\hline & Base of second dorsal fin & 35.0 & $33.5-41.7$ & 38.9 \\
\hline & Second dorsal fin depth & 16.2 & $11.3-19.1$ & 15.5 \\
\hline & Origin of anal fin & 48.8 & $48.9-64.0$ & 52.7 \\
\hline & Base of anal fin & 37.7 & $26.2-39.1$ & 35.9 \\
\hline & Peduncle length & 9.0 & $10.2-13.8$ & 12.1 \\
\hline
\end{tabular}

$\mathrm{AV}=$ absolute values. 
Table 2

Meristic data of Chiasmodon harteli

\begin{tabular}{llll}
\hline Character & This study & $\begin{array}{l}\text { Species range } \\
\text { (Melo 2009) }\end{array}$ & $\begin{array}{l}\text { Mode } \\
\text { (Melo 2009) }\end{array}$ \\
\hline First dorsal-fin rays & XII & X-XIII & XI \\
Second dorsal-fin rays & destroyed & iii-iv, 23-27 & iii, 25 \\
Anal-fin rays & iii, 28 & iii-v, 21-28 & iv, 25 \\
Pelvic-fin rays & I, 6 & I,5 & I, 5 \\
Pectoral-fin rays & 13 & $12-14$ & 13 \\
Caudal-fin rays & i, $7,8, \mathrm{i}$ & i, 7-8, 8-7, i & i, 7, $8, \mathrm{i}$ \\
Vertebrae & 47 & $47-48$ & 47 \\
\hline
\end{tabular}

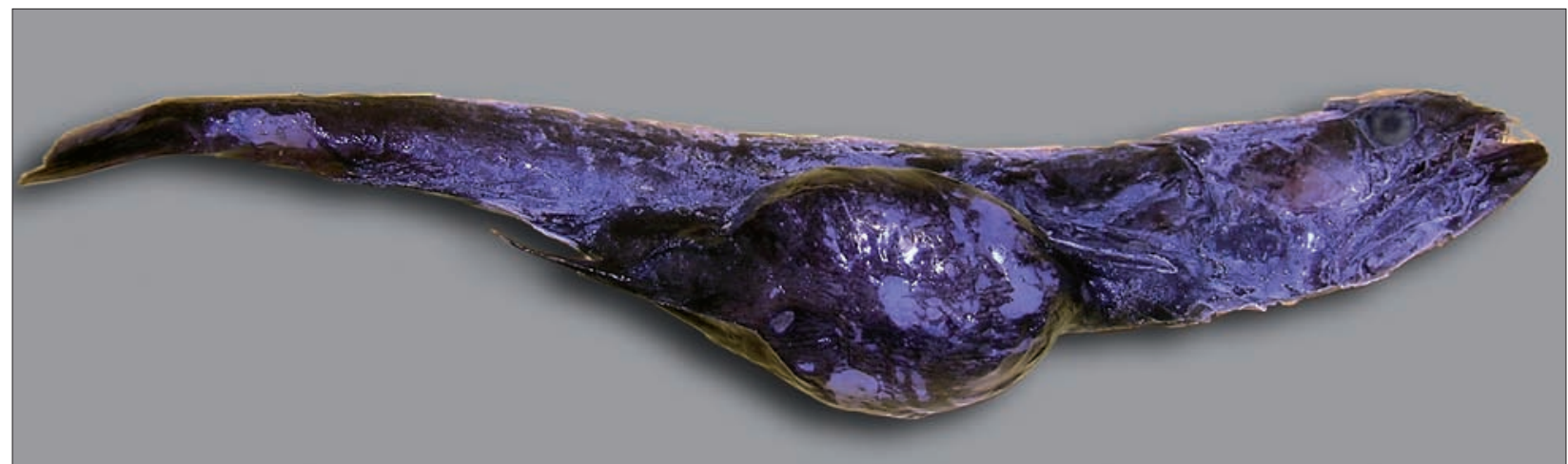

Fig. 1. Specimen of Chiasmodon harteli caught off the south-eastern coast of Greenland (161 mm TL; collection deposit number DFS/4-3-38-6-1; photo: A. Brysiewicz)

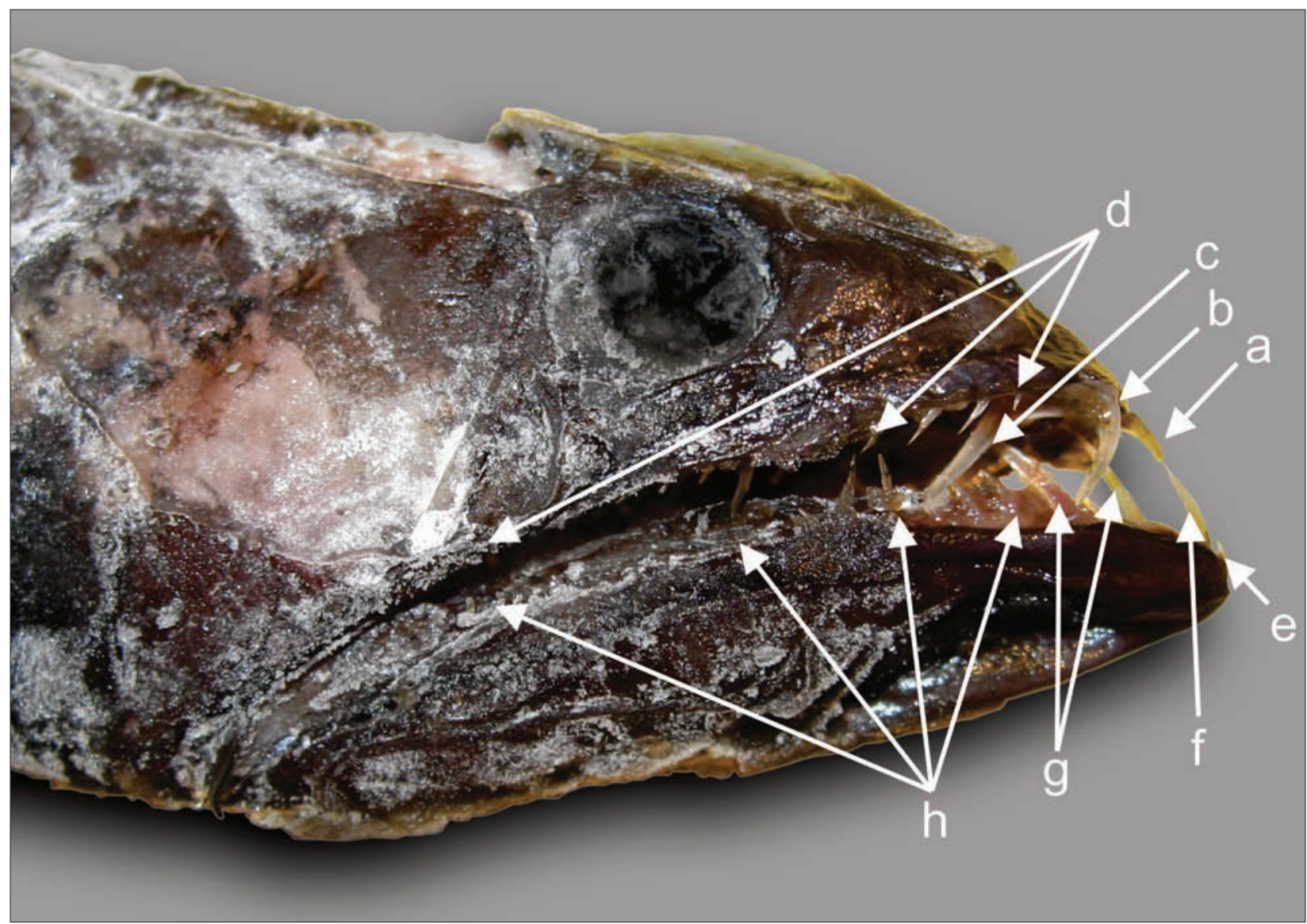

Fig. 2. Head of Chiasmodon harteli with dentition pattern on the premaxilla $(\mathrm{a}-\mathrm{d})$ and dentary $(\mathrm{e}-\mathrm{h})$ : $\mathrm{a}=$ accessory anterior tooth; $\mathrm{b}=$ canine; $\mathrm{c}=$ fang; $\mathrm{d}=$ lateral series (mesial series not visible); $\mathrm{e}=$ teeth at anterior edge; $\mathrm{f}=$ canine; $\mathrm{g}=$ mesial series; $\mathrm{h}=$ lateral series (Photo: Karolina Półtorak) 


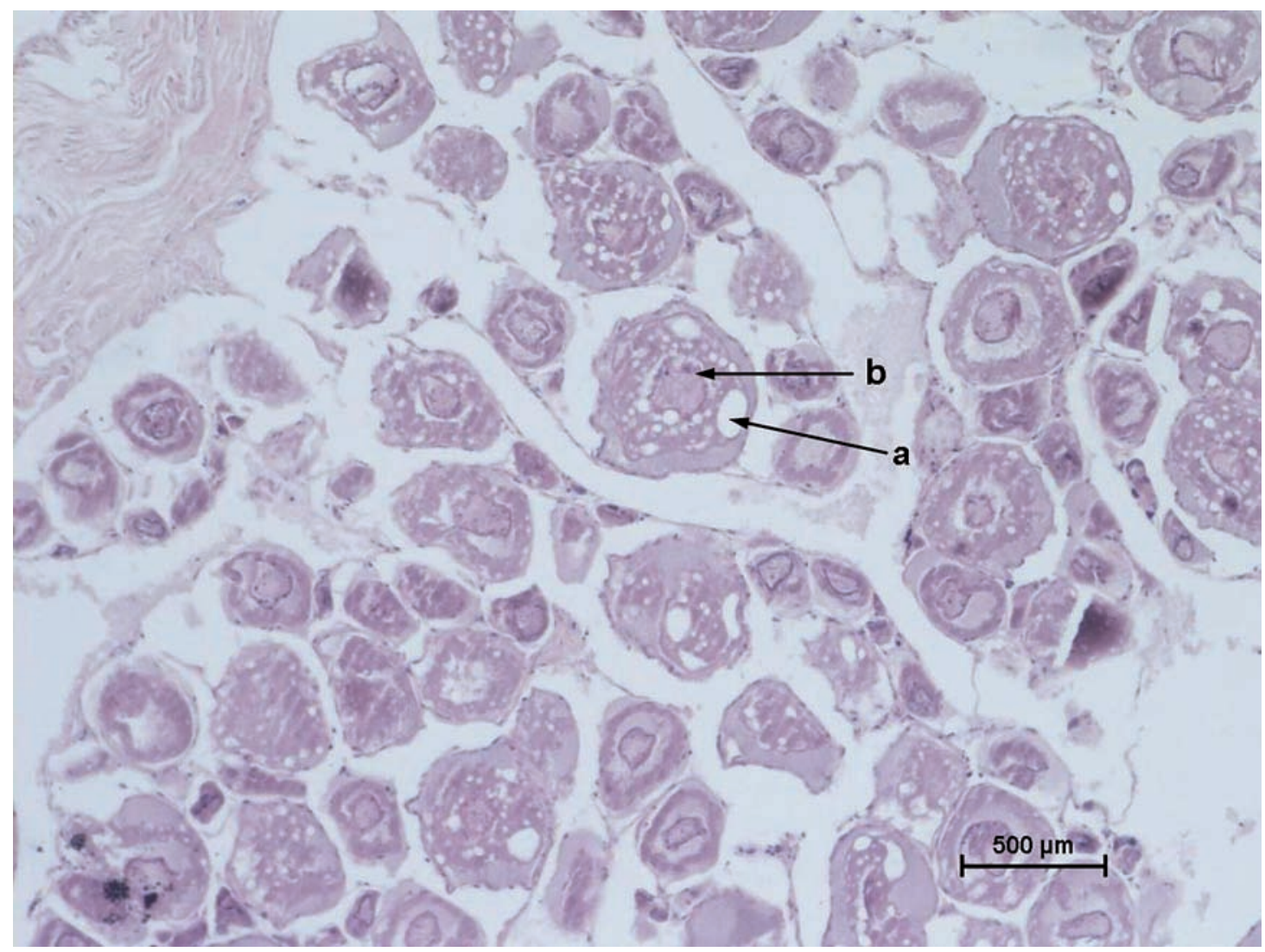

Fig. 3. Chiasmodon harteli; Oocytes in early vitellogenesis: $\mathrm{a}=$ yolk formation in vitellogenic follicles; $\mathrm{b}=$ nucleus with nucleoli

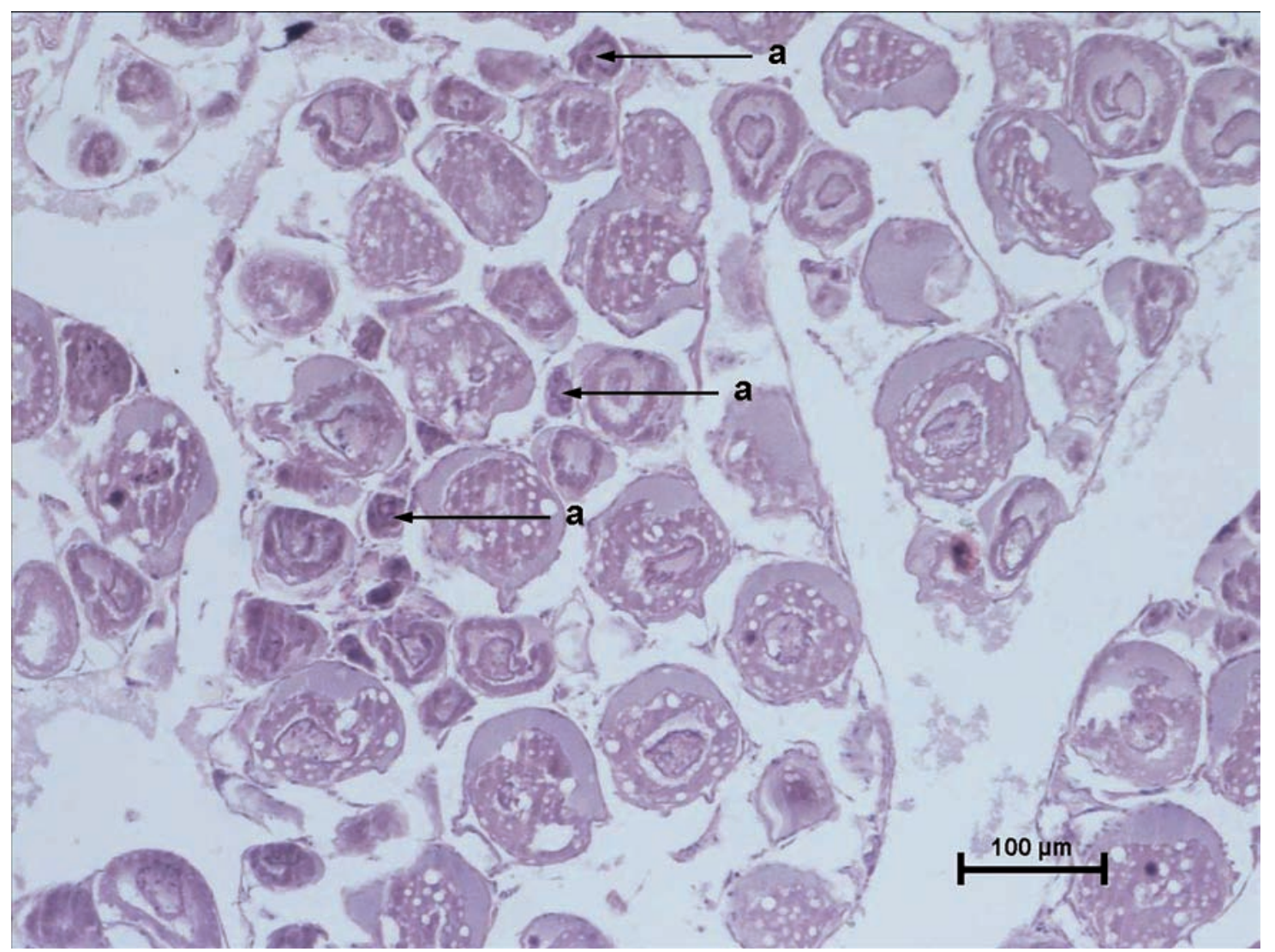

Fig. 4. Chiasmodon harteli; Ovaries' dissection with the oogonies visible; $a=$ oogonies 
of oogonies were also present, smaller than the oocytes but staining more strongly with haematoxylin (Fig. 4).

A single species of parasite was found, Anisakis simplex (Rudolphi, 1809) (Nematoda: Anisakidae). A total of six larvae were found, all of which were in larval stage L3, encysted. Four larvae were found in the body cavity, and two in the peritoneum. A. simplex has not yet been reported from a fish representing this genus.

No data were collected on food of $C$. harteli. The stomach, although markedly extended was empty.

\section{DISCUSSION}

The specimen collected fits the distribution of C. harteli, the only species of Chiasmodon which occurs that far north (Melo 2009, Møller et al. 2010).

The specimen reported herein fits the morphometric description provided by Melo (2009), with some non significant differences which may be explained by a broader range of morphometric characteristics. For example, the snout of $C$. harteli is elongate and pointed $(23.0 \%-26.6 \%$ HL according to Melo (2009), whereas the specimen presently examined had longer snout (30.8\%), but upper jaw [74.3\%-84.2\% HL in Melo (2009), vs. $72.9 \%$ HL in this study] and lower jaw [80.8\%-89.9\% HL in Melo (2009), vs. 77.9\% HL, respectively] were slightly shorter.

There is still very few morphometric data published, on $C$. harteli, and more results are urgently needed to improve our knowledge on this rare species.

In chiasmodontids, the very distensible body walls allow females to have extremely enlarged gonads. In the specimen studied, however, the eggs were in the first stage of development and the ovaries were not hypertrophied. All oocytes along the whole length of ovarian wall were in an early stage of vitellogenesis what could point to start spawning likely not sooner than in late autumn/winter. The ovary observed in $C$. harteli female could be determined as a hollow sac-like organ, formed by the fusion of edges of the two ovigerous folds, like in most teleost fishes. In order to estimate a real time of spawning onset, more material to study is needed, including both ovaries and testes. However, during four seasons (2006-2009) of trawling (during the commercial catches of the Greenland halibut) of $M / T$ ODRA, only one specimen of $C$. harteli was observed (Wiesław Szaszkiewicz: personal information). Earlier, the trawling of $R / V$ SHINKAI-MARU in the Subarctic area within 1988-92 yielded 40 specimens (1 holotype and 39 paratypes) of C. harteli (see Melo 2009). Assessment of its abundance would be difficult, because deepwater fishes are rarely captured.

The specimen examined had an enlarged stomach, although completely empty (Fig. 1). Possibly the stomach content was regurgitated after capture. Some chiasmodontids have been found with a partially digested fish half inside the oesophagus and half in the mouth (Marcelo Melo: unpublished).

Nematodes are common parasites of chiasmodontids in general, and are often found in the liver, digestive tract, and body walls (Marcelo Melo: unpublished). Small nematodes were present in the abdominal cavity in some of Pseudoscopelus and Chiasmodon (see Prokofiev and Kukuev 2009), but the authors did not identify them up to the species level. In the specimen reported herein, the parasites $A$. simplex were present only in the body cavity and peritoneum.

Anisakis simplex is widespread between lat $35^{\circ} \mathrm{N}$ and the Arctic Polar Circle, in both the western and eastern Atlantic (Mattiucci and Nascetti 2006). It is a common parasite of deep-sea fishes and has very narrow host specificity (Klimpel et al. 2006, 2007, 2010). The definitive hosts of anisakid nematodes are marine mammals, such as cetaceans and, sometimes, pinnipeds. The eggs of A. simplex are excreted into the sea along with the mammal faeces. Eggs embryonate and hatch into the L2-L3 larvae, becoming free-swimming larvae sheathed by the second stage cuticle. Those are eaten by planktonic copepods or euphausiid shrimps, which are the obligatory first intermediate hosts. In the haemocoel of the crustacean they hatch. The crustaceans are eaten, and infect, planktivorous fish, which are the obligatory second intermediate hosts. The cycle is closed when the fish are eaten by marine mammals and the $A$. simplex moults into the stage L4 and develops into the adult (Køie et al. 1995, Anderson 2000). Sometimes, however, the obligatory second intermediate host can be eaten by a piscivorous fish or a cephalopod, which will serve as paratenic hosts. The larvae of $A$. simplex are transmitted into the new paratenic host via the food chain, and stage L3 does not need to undergo a new moult (Klimpel et al. 2004). Chiasmodon harteli is one of those cases. It is a piscivorous species which probably undergoes a diel vertical migration for feeding on planktophagous or other piscivorous fish (Melo 2009). Klimpel (2010) demonstrated that $A$. simplex has low host specificity, but the parasites are less abundant in hosts than in the obligatory second intermediate hosts.

\section{ACKNOWLEDGMENTS}

Authors thank Mr. Wiesław Szaszkiewicz for collecting and donating the specimen of C. harteli and $\mathrm{Mr}$. Michał Więcaszek for technical support. MRSM received financial support from the Brazilian Agency FAPESP (process\# 2010/50322-6).

\section{REFERENCES}

Anderson R.C. 2000. Nematode parasites of vertebrates: their development and transmission. Oxford University Press/CABI Publishing.

Johnson R.K., Keene M.J. 1986. Chiasmodontidae. Pp. 517-1007. In: Whitehead P.J.P., Bauchot M.-L., Hureau J.-C., Nielsen J., Tortonese E. (eds.) Fishes of the north-eastern Atlantic and the Mediterranean. Vol. 2. UNESCO, Roma.

Klimpel S., Palm H.W., Rückert S., Piatkowski U. 2004. The life cycle of Anisakis simplex in the Norwegian Deep (north North Sea). Parasitology Research 94 (1): 1-9. DOI: $10.1007 / \mathrm{s} 00436-004-1154-0$

Klimpel S., Palm H.W., Busch M.W., Kellermanns E. Rückert S. 2006. Fish parasites in the Arctic deep-sea: Poor 
diversity in pelagic fish species vs. heavy parasite load in a demersal fish. Deep Sea Research I 53 (7): 1167-1181. DOI: $10.1016 /$ j.dsr.2006.05.009

Klimpel S., Palm H.W., Bush M.W., Kellermanns E. 2007. Fish parasites in the bathyal zone: The halosaur Halosauropsis macrochir (Günter, 1878) from the MidAtlantic Ridge. Deep Sea Research II 55 (1-2): 229-235. DOI: 10.1016/j.dsr2.2007.09.006

Klimpel S., Busch M.W., Sutton T., Palm H.W. 2010. Mesoand bathy-pelagic fish parasites at the Mid-Atlantic Ridge (MAR): Low host specificity and restricted parasite diversity. Deep Sea Research I 57 (4): 596-603.

DOI: $10.1016 /$ j.dsr.2010.01.002

Køie M., Berland B., Burt M.D.B. 1995. Development to third-stage larvae occurs in the eggs of Anisakis simplex and Pseudoterranova decipiens (Nematoda, Ascaridoidea, Anisakidae). Canadian Journal of Fisheries and Aquatic Sciences 52 (S1): 134-139.

DOI: $10.1139 / \mathrm{f} 95-519$

Mattiucci S., Nascetti G. 2006. Molecular systematics, phylogeny and ecology of anisakid nematodes of the genus Anisakis Dujardin, 1845: an update. Parasité 13 (2): 99-113.

Melo M.R.S. 2009. Revision of the genus Chiasmodon (Acanthomorpha: Chiasmodontidae), with the description of two new species. Copeia 2009 (3): 583-608.

DOI: $10.1643 / \mathrm{CI}-08-048$

Melo M.R.S., Walker H.J.jr., Klepadlo C. 2007. Two new species of Pseudoscopelus (Teleostei: Chiasmonontidae), with a new diagnosis for the genus. Zootaxa 2007 (1605): 33-46.
Merson R.R., Casey C.S., Martinez C., Soffientino B., Chandlee M., Specker J.L. 2000. Oocyte development in summer flounder: seasonal changes and steroid correlates. Journal of Fish Biology 57 (1): 182-196.

DOI: $10.1111 / j .1095-8649.2000 . t b 00785 . x$

Møller P.R., Nielsen J.G., Knudsen S.W., Poulsen J.Y., Sünksen K., Jørgensen O.A. 2010. A checklist of the fish fauna of Greenland waters. Zootaxa 2010 (2378): 1-84.

Prokofiev A.M., Kukuev E.I. 2009. Systematics and distribution of black swallowers of the genus Chiasmodon (Perciformes: Chiasmodontidae). Journal of Ichthyology 49 (10): 899-939.

DOI: $10.1134 / \mathrm{S} 0032945209100063$

Wiley E.O., Johnson G.D. 2010. A teleost classification based on monophyletic groups. Pp. 123-182. In: Nelson J.S., Schultze H.-P., Wilson M.V.H. (eds.) Origin and phylogenetic interrelationships of teleosts. Verlag Dr. Friedrich Pfeil, München, Germany.

Zha J., Wang Z., Wang N., Ingersoll C. 2007. Histological alternation and vitellogenin induction in adult rare minnow (Gobiocypris rarus) after exposure to ethynylestradiol and nonylphenol. Chemosphere 66 (3): 488-495.

DOI: 10.1016/j.chemosphere.2006.05.071

Received: 18 September 2011

Accepted: 5 December 2011

Published electronically: 31 December 2011 